\title{
Note on the Endemic Status of Harran Fringe-fingered Lizard, Acanthodactylus harranensis Baran, Kumlutaş, Lanza, Sindaco, Ilgaz, Avc1, \& Crucitti, 2005
}

\author{
John MULDER
}

Holhorstweg 4, 7341AC Beemte Broekland, the Netherlands

ORCID ID: John MULDER: https:// orcid.org/0000-0003-3746-1700

\begin{abstract}
Received: 06.12 .2020
Accepted: 05.03 .2021

Published online: 31.03 .2021

Issue published: 30.06 .2021

Abstract: Harran Fringe-fingered Lizard, Acanthodactylus harranensis has been assumed to be endemic to Turkey so far. Here an ancient personal finding from Syria is presented that was recorded ten years before the classification of the species. The newly acquired distributional data of this endangered species is discussed, including the consequences about the survival of the species.
\end{abstract}

Keywords: Turkey, Syria, Mesopotamian Plain, Harran Fringe-Fingered Lizards, endemism.

\section{Harran Tarak Parmakl1 Kertenkelesi, Acanthodactylus harranensis'in Baran, Kumlutaş, Lanza, Sindaco, Ilgaz, Avc1, \& Crucitti, 2005 Endemik Statüsü Hakkında Bir Not}

\begin{abstract}
Öz: Harran Kertenkelesi, Acanthodactylus harranensis'in şimdiye kadar sadece Türkiye'ye endemik olduğu varsayılmaktaydı. Bu çalışmayla, türün tasnifinden on yıl önce Suriye'den eski bir kişisel bulgu sunulmuştur. Nesli tükenmekte olan türün yeni elde edilen dağılış verileri ve türün devamlılığı da dahil olmak üzere tartışılmıştır.
\end{abstract}

Anahtar kelimeler: Türkiye, Suriye, Mezopotamya ovası, Harran Kertenkelesi, endemizm.

Mayıs 1995'te Suriye'nin kuzey kesimlerinde, Türkiye sınırına yakın bir bölgede, yapılan arazi çalışması sirasında tahıl tarlasının kenarında bulunan sı̆ bir hendekte Acanthodactylus Fitzinger, 1834 cinsine ait bir örneğe rastlanmıştır (Şekil 1). Erkek numunenin yakalandığı lokalite haritada tespit edilememiş olup, yerel tabelada Bi'r Abou olarak adlandırılan yerleşim biriminin $9 \mathrm{~km}$ batisinda $\left(36.666^{\circ} \mathrm{N} 39.679^{\circ} \mathrm{E}\right)$ bulunmaktadir. Kertenkele örneği elle yakalandıktan sonra renk-desen özelliklerinin tespiti için fotoğrafı çekilmiştir. Örnek eterle bayıltıldıktan sonra önceden hazırlanmış uygun tespit karışımı (\%70'lik etanol) vücut boşluğuna enjekte edilmiştir. Örnek hâlihazırda Rotterdam Doğa Tarihi Müzesi'nde muhafaza edilmektedir (Müze numarası 95215). Örneğe ait bazı morfolojik karakteristikleri (pholidosis, vücut ölçümü ve oranlar) o zaman belirlenmiştir.

Toplanan örneğin bazı morfolojik özellikleri $A$. grandis Boulenger, 1909 türüne yakın olmakla birlikte (parmaklarda dört sıra pul, ventral plakların eğik dizilmesi gibi), ergin erkek örnek bazı farklı özellikler göstermekteydi ve o yıllarda mevcut olan literatürler ile (Arnold, 1983; Salvador, 1982) numunenin taksonomik durumu net olarak belirlenememiştir.

Ergin erkek numuneye ait bazı morfolojik özellikler şu şekilde sıralanabilir: Baş+gövde uzunluğu $97 \mathrm{~mm}$; kuyruk rejenere olmuş; ventralia enine 12-14 sıra; ventralianın konfigürasyonu komplike, yani merkez kısmında uzunlamasına sıra halinde, öncesi ve arkasında eğik sıralar halinde; parmaklarda dört sıra pul; kulak açıklığının önündeki pulların pektinatlı; subocularis dördüncü ve beşinci supralabial arasına sıkışmış, ama dudak kenarına kadar ulaşmıyor; gularia 30; dorsalia 52; collaria 11; femoral porlar (sol) 25; kuyruğun proksimal pulları neredeyse düz, sonrasında karinalı; başın yan tarafında 5 koyu dikey bant mevcut; sırt tarafı ağ şeklinde desenli.

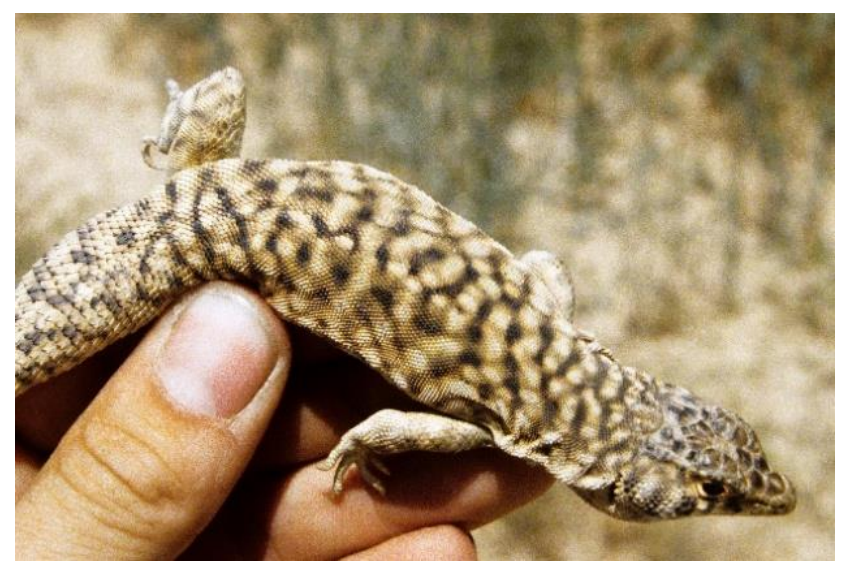

Şekil 1. Suriye'nin kuzeyinde $\left(36.666^{\circ} \mathrm{N} 39.679^{\circ} \mathrm{E}\right)$ gözlenen Acanthodactylus harranensis örneği

Figure 1. Acanthodactylus harranensis specimen from Northern Syria $\left(36.666^{\circ} \mathrm{N} 39.679^{\circ} \mathrm{E}\right)$

Baran et al. (2005) on yıl sonra Harran' dan (Şanlıurfa, Türkiye) yeni bir Lacertid türü olarak Acanthodactylus harranensis türünü tanımlamıştır. Yeni takson sadece tip lokalitesi olan Harran harabelerinden rapor edildiğinden 
Türkiye' ye endemik olarak kabul edilmektedir (Baran et al., 2021).

Suriye'de Acanthodactylus cinsine dahil 5 türün [A. boskianus asper (Audouin, 1829), A. grandis Boulenger, 1909, A. orientalis Angel, 1936, A. robustus Werner, 1929 ve A. tristrami (Günther, 1864).] var olduğu bilinmektedir (lacerta.de). Söz konusu türler göz önünde bulundurulduğunda, A. orientalis, A. robustus, A. tristrami ve $A$. boskianus subocular plağın dudak kenarına ulaşması, parmaklarında üç sıra pulun varlığı ve ventral plaklarının tam uzunlamasına sıra teşkil etmeleri ile A. harranensis türünden ayrışmaktadırlar (Baran et al., 2005).

Suriye'de bulunan tek bir örneğin morfolojik özellikleri A. harranensis türüne birebir uygunluk göstermektedir. Mevcut örnek, ventral plakların sayısı ve konfigürasyonunun yanında, kuyruğun proksimal pullarının neredeyse düz olması ve tipik sırt deseninden (ağsı), A. grandis türünden farklılık göstermektedir. Ayrıca sirt ortasındaki enine bir siradaki dorsal pulların sayısının (52) az olmasiyla da Suriye'de bulunan A. grandis türünden (56-63, Salvador, 1982) farklılık göstermektedir.

Numunenin bulunduğu lokalite ile Türkiye sınırı arasında 7 km, Harran İlçesi (Şanlıurfa) (Tip lokalite) ile ise kuş bakışı $61 \mathrm{~km}$ mesafe bulunmaktadır. Türün tip lokalitesinin yanında ve mevcut çalışmada incelenen örneğin yakalandığı lokalite, aşağıda Şekil 2' de verilmiştir. Söz konusu iki lokalite Mezopotamya Ovası'nın aynı kuzey bölümünde yer almaktadır.

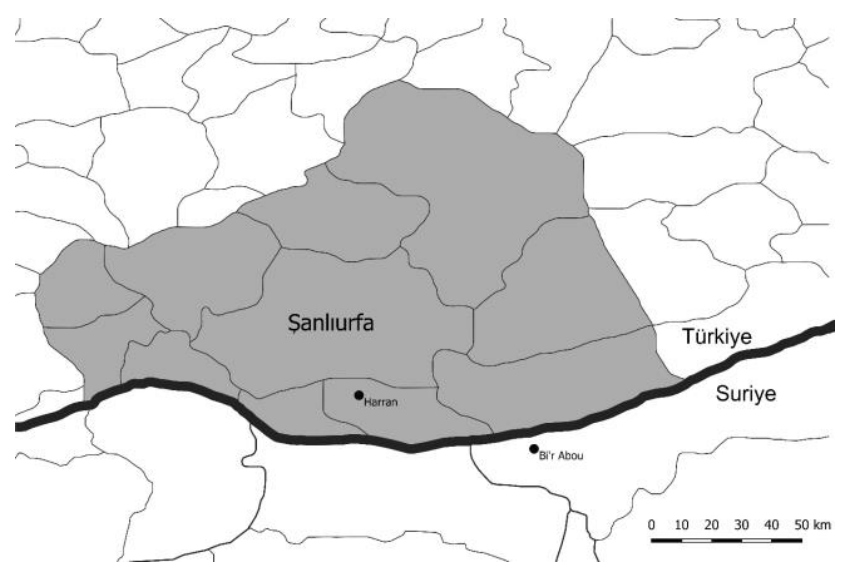

Şekil 2. Acanthodactylus harranensis'in tip lokalitesini ve Suriye'de bulunan yeni lokaliteyi gösteren harita.

Figure 2. The map showing the type locality of Acanthodactylus harranensis and the new locality found in Syria.

Bu çalışmayla Harran Tarak Parmaklı Kertenkelesi'nin Türkiye ile birlikte Suriye'de de yayılış gösterdiği ortaya konulmuş ve tür endemik olma statüsünden çıkmıştır. Acanthodactylus harranensis muhtemelen Mezopotamya'nın kuzey parçasına endemik bir kertenkele türüdür. Daha önce kurak bir yapıda olan Harran Ovası, 1995 yılından itibaren Atatürk Barajı suları ile sulanmaya başlanmış ve Suriye sınırına kadar olan türün yaşamasına uygun alanlar tarlalara dönüştürülmüştür. Söz konusu durum Güneydoğu Anadolu Bölgesi'nde Harran Tarak Parmaklı Kertenkelesi'nin yarı kurak olan orijinal habitatının yok olması sonucunu beraberinde getirmiştir. Nesli tehlike altında olan türün (Kaska et al., 2009), özellikle Suriye' nin kuzeyinde yer alan sulanmayan sahalarda varlığını sürdürme şansı mevcuttur. Suriye içerisinde kalan bölge yeterince araştırılmamıştır. Bilinen populasyonu oldukça yaşlı bireylerden oluşan türün (Beşer et al., 2019), dağılış sahasının tam olarak belirlenmesi için özellikle Suriye'nin kuzeyi başta olmak üzere Türkiye-Suriye sınırı boyunca daha kapsamlı arazi çalışması yapılması gerekmektedir. Bölgenin güvenlik durumu şu aşamada buna imkan tanımamaktadır.

Etik kurul onayı: Bu çalışma için etik kurul onayı alınmasına gerek yoktur.

Çıkar çatışması: Yazar, çıkar çatışması olmadığını beyan etmiştir.

\section{Kaynaklar}

Arnold, E.N. (1983). Osteology, genitalia and the relationships of Acanthodactylus (Reptilia: Lacertidae). Bulletin of the British Museum (Natural History) (Zoology Series), 44(5), 291-339.

Baran, İ, Kumlutaş, Y., Lanza, B., Sindaco, R., Ilgaz, Ç, Avcı, A., \& Crucitti, P. (2005). Acanthodactylus harranensis, a new species of lizard from southeastern Turkey (Reptilia: Sauria: Lacertidae). Bollettino del Museo regionale di Scienze naturali, Torino, 23(1), 323-341.

Baran, İ, Avcl, A., Kumlutaş, Y., Olgun, K., \& Ilgaz, Ç. (2021). Türkiye Amfibi ve Sürüngenleri. Ankara, Türkiye, Palme Yayınevi, 230 pp.

Beşer, N., Ilgaz, Ç., Kumlutaş, Y., Avc1, A., Candan, K., \& Üzüm, N. (2019). Age structure and body size of a critically endangered species, Acanthodactylus harranensis (Squamata: Lacertidae) and its demography. Animal Biology, 69, 421-431. https://doi.org/10.1163/15707563$\underline{20191067}$

Kaska, Y., Kumluta s, Y., Avcl, A., Üzüm, N., Yeniyurt, C., Akarsu, F. \& Sindaco, R. (2009) Acanthodactylus harranensis. The IUCN Red List of Threatened Species 2009: e.T164562A5908003. Available from: http://www.iucnredlist.org/details/full/164562/0 (downloaded on 12 January 2018).

Salvador, A. (1982). A revision of the lizards of the genus Acanthodactylus (Sauria: Lacertidae). Bonner zoologische Monographien, 16, 1-167. 